\title{
Unusual muscle disease in HIV infected patients
}

\section{S Roedling, D Pearl, H Manji, M G Hanna, J L Holton, R F Miller}

Sex Transm Infect 2004;80:315-317. doi: 10.1136/sti.2003.008474

Two patients presented with proximal muscle weakness, a normal or minor elevation of creatine phosphokinase (CPK) and normal findings on electromyography. Muscle biopsy in one patient revealed CD8+ polymyositis, and in the other showed ddl induced myopathy. These cases illustrate the importance of muscle biopsy in identifying the underlying pathology in HIV infected patients with muscle weakness and little or no abnormality in laboratory investigations.

$\mathrm{H}$ IV infected patients may develop a variety of muscular disorders including HIV associated polymyositis, ${ }^{12}$ myopathy induced by nucleoside reverse transcriptase inhibitors (NRTI), such as zidovudine, ${ }^{3}$ opportunistic infections including Toxoplasma gondii, ${ }^{5}$ infiltration by tumour, ${ }^{6}$ HIV associated vasculitis, ${ }^{7}$ and rhabdomyolysis caused by HIV itself or by drugs including didanosine. ${ }^{8}$ Many of these conditions present with overlapping non-specific symptoms of fatigue and myalgia. Biochemical abnormalities of muscle function (creatine phosphokinase (CPK) and aldolase) occur in approximately $15 \%$ of asymptomatic HIV infected patients, ${ }^{9}$ but may not be good markers of muscle inflammation in HIV infected patients undergoing evaluation of possible muscle disease. ${ }^{210}$ In order to define the nature of underlying muscle disease, if any, in a symptomatic HIV infected patient muscle biopsy is necessary. We describe two HIV infected patients with proximal muscle weakness and a

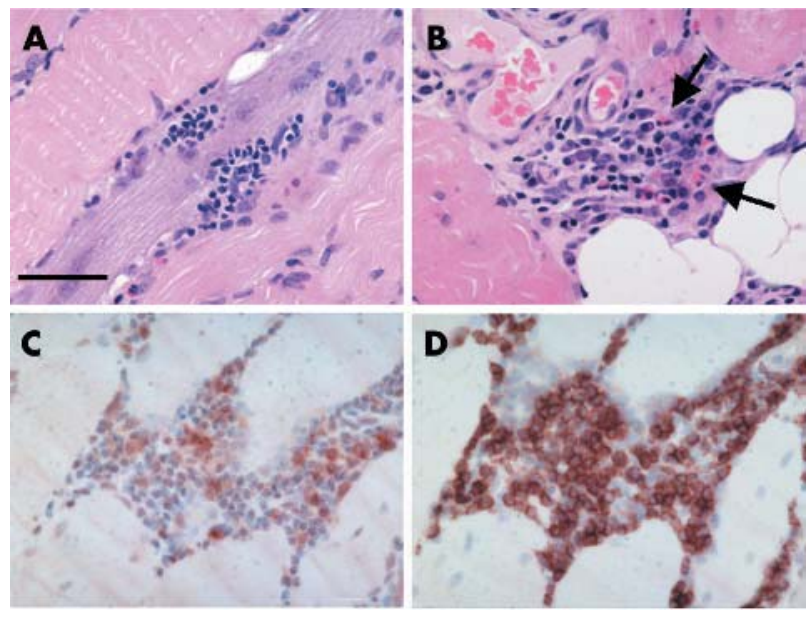

Figure 1 Histological examination showed focal endomysial and perivascular inflammation with occasional infiltration of intact fibres by ymphocytes (A). The inflammatory infiltrate was composed predominantly of lymphocytes with additional eosinophils, plasma cells, and macrophages ( $\mathrm{B}$, arrows indicate eosinophils).

Immunohistochemical staining demonstrated small numbers of CD4 positve T lymphocytes (C) with larger numbers of lymphocytes expressing CD8 (D). (A) and (B) haematoxylin and eosin; (C) CD4

immunohistochemical staining; (D) CD8 immunohistochemical staining. Bar in (A) represents $50 \mu \mathrm{m}$ in all panels. normal or minor elevation of CPK and normal electromyography (EMG) findings, in whom muscle biopsy revealed a specific diagnosis.

\section{Case 1}

A 50 year old black African woman presented with a 4 week history of leg weakness, with difficulty walking and climbing stairs. She had been diagnosed HIV-1 antibody positive 3 months previously; at which time an eosinophilia of 1.1 (normal range $0.04-0.44) \times 10^{9} / 1$ was noted. On admission to hospital, examination of the legs showed normal tone and proximal weakness $($ power $=$ MRC grade 4/5). Ankle and knee reflexes were absent and plantars were flexor. The gait was waddling in nature. She had marked difficulty standing from sitting. The thigh muscles were tender to palpation. General examination was normal.

A full blood count $(\mathrm{FBC})$ showed eosinophilia $\left(1.66 \times 10^{9} / 1\right)$ and a normochromic, normocytic anaemia: the erythrocyte sedimentation rate $(E S R)=49 \mathrm{~mm}$ in the first hour, $\mathrm{CPK}=547(\mathrm{~N}=24-173) \mathrm{U} / \mathrm{l}$. Renal, liver, and thyroid function tests were normal, as were calcium and phosphate. The CD4 count was 340 cells $\times 10^{6} / 1$ and CD8 count was 3450 $($ normal $=90-990)$ cells $\times 10^{6} / 1:$ CD4:CD8 ratio $=0.1$ (normal $=1.00-2.50)$. Serological tests for syphilis and an autoimmune screen were negative. Stool microscopy for ova, cysts and parasites, and terminal urine screening for Schistosoma spp ova was negative. Serology for Strongyloides spp, Bartonella spp, Trichinella spp, cystercicosis, Lyme, and Filaria spp was negative.

A plain radiograph of the thighs was normal. Cranial magnetic resonance imaging showed generalised atrophy and widespread leucoencephalopathy. CSF analysis showed protein $=1.72 \mathrm{~g} / \mathrm{l}$, glucose $=2.5($ plasma glucose $=5.0) \mathrm{mmol} / \mathrm{l}$, and cell count $=178$ lymphocytes $/ \mathrm{ml} \quad(87 \%$ were CD8+ lymphocytes); culture for bacteria, mycobacteria, and fungi was negative. Serology for cryptococcal antigen, HTLV-1 and HTLV-2, syphilis, and $T$ gondii was negative. Herpesviruses 1-8, enteroviruses, JC virus and Mycobacterium tuberculosis were not detected by polymerase chain reaction (PCR) amplification.

Nerve conduction studies and EMG were non-diagnostic. Muscle biopsy of left vastus lateralis showed multiple foci of inflammatory cells with occasional infiltration of intact muscle fibres by lymphocytes without granulomata or vasculitis. The inflammatory infiltrate consisted of mature lymphocytes, macrophages, plasma cells, and eosinophils. Immunohistochemical staining showed the lymphocytes were predominantly CD8+ T cells with smaller numbers of CD4+ T lymphocytes (CD8: C8/144B, Dako, Glostrup, Denmark; CD4: RTU-CD4-1F6, Novacastra, Newcastle, UK) (fig 1) and identified a smaller component of B lymphocytes (CD20: L26, Dako); macrophages expressed CD68 (PG-Ml,

Abbreviations: CPK, creatine phosphokinase; EMG,

electromyography; ESR, erythrocyte sedimentation rate; $F B C$, full blood count; NRTI, nucleoside reverse transcriptase inhibitors 
Dako). Ziehl Neelsen, Gram, and Grocott stains showed no evidence of mycobacterial, bacterial, or fungal infection.

The patient began combination antiretroviral therapy with lamivudine, didanosine, and lopinavir and mobilised rapidly. At repeat lumbar puncture, after 2 weeks of antiretroviral therapy, the CSF protein had fallen to $1.1 \mathrm{~g} / \mathrm{l}$ and the lymphocyte count had fallen to 110 cells $\times 10^{6} / 1$. After 3 months of antiretroviral therapy the patient was asymptomatic, HIV viral load was undetectable, peripheral blood CD4 count $=310$ cells $\times 10^{6} / 1$, the CD8 count had fallen to 1810 cells $\times 10^{6} / 1(\mathrm{CD} 4: \mathrm{CD} 8=0.17)$, and CPK and eosinophil count were normal.

\section{Case 2}

A 51 year old white homosexual man, HIV-1 antibody positive for 10 years, presented with a 2 year history of progressive leg weakness, manifest as difficulty walking and cycling uphill. Six and a half years before the current presentation he had begun combination antiretroviral therapy with zidovudine and lamivudine. This regimen had been modified to didanosine with ritonavir after 3 months, because of marrow toxicity. The patient had taken the latter regimen for over 6 years at the time of presentation with leg weakness. There was no family history of neurological disease. On examination there was weakness of hip flexion $(\mathrm{MRC}=4 / 5)$ and the thigh muscles were wasted and nontender: there was no muscle fasciculation. Power, reflexes, sensation, and coordination were otherwise normal in the arms and legs. Gait and cranial nerve examination were normal. General examination was normal.

A FBC, renal, liver, and thyroid function tests, CPK, random glucose, resting venous lactate, autoantibody screen, ESR, and $\mathrm{C}$ reactive protein were normal. The CD4 count $=220$ cells $\times 10^{6} / 1$ and HIV viral load $=200$ copies $/ \mathrm{ml}$. An EMG and nerve conduction studies revealed a mild sensorimotor neuropathy (sensory predominance) with no evidence of myopathy. A left vastus lateralis muscle biopsy showed multiple ragged red fibres identified using immunohistochemical staining for mitochondria (ab3298, abcam, Cambridge, UK). There was no evidence of inflammation or fibre necrosis. Ultrastructural examination demonstrated several fibres containing abnormal mitochondria several of which were enlarged with an annular arrangement of the internal membranes while many others contained type I paracrystaline inclusions (fig 2). In the light of the muscle biopsy results didanosine and ritonavir were stopped and abacavir, lamivudine, and nelfinavir were started. At follow up 2 months after starting the new antiretroviral drugs the patient was asymptomatic and had an undetectable viral load.

\section{DISCUSSION}

In both these patients with non-specific presentations, minor abnormalities of CPK and normal results from electromyography, a specific diagnosis was made by muscle biopsy. In the first case the lymphocytic infiltrate of muscle consisted largely of CD8+ lymphocytes, a finding typical of HIV associated polymyositis. ${ }^{11}$ The associated CD8+ lymphocytosis in peripheral blood and in CSF, despite the absence of sicca symptoms or parotid enlargement, suggests that this patient had diffuse infiltrative lymphocytosis syndrome (DILS). ${ }^{11-13}$ In one case series of 35 patients with DILS nine $(26 \%)$ had an inflammatory myositis ${ }^{13}$ : in these nine patients the lymphocytic muscle infiltrate was not phenotyped. By extrapolation from other studies of HIV associated polymyositis, ${ }^{11}$ it is likely that these patients had a CD8+ lymphocytic infiltrate of muscle. The case described here is also unusual in respect of the finding in CSF of a CD8+ lymphocytic pleocytosis, which responded to antiretroviral

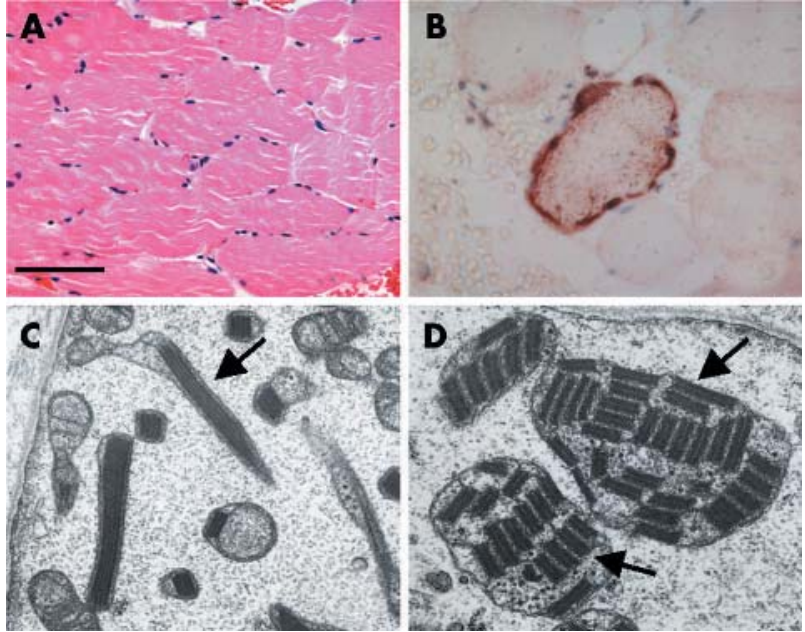

Figure 2 Histological examination showed no evidence of inflammation or necrosis (A). Many ragged red fibres were identified (B) and these were shown on ultrastructural examination to contain abnormal mitochondria many containing type I paracrystaline inclusions (arrows in C and D). (A) Haematoxylin and eosin; (B) immunohistochemical staining for mitochondria; (C) and (D) electron micrographs. Bar represents $100 \mu \mathrm{m}$ in (A), $50 \mu \mathrm{m}$ in (B), $850 \mathrm{~nm}$ in (C), and $550 \mathrm{~nm}$ in (D).

therapy. This has not been reported previously as a manifestation of DILS, but Itescu et al, in the original description of DILS, reported that three of 17 patients had "aseptic meningitis." ${ }^{12}$ In these three patients the CSF cell types and their phenotype were not reported and no repose to antiretroviral therapy was recorded. ${ }^{12}$

Eosinophilic infiltration of muscle has not previously been described in HIV associated polymyositis/DILS. Common infectious causes include the helminths Trichinella, Taenia solis, and the protozoan $T$ gondii. ${ }^{14}$ These and other infections were excluded by negative findings on microscopy of the muscle biopsy and by negative serological tests. The negative autoantibody screen and the absence of vasculitis on histology of the muscle excluded connective tissue disease, polyarteritis nodosa, and Churg-Strauss as causes of the eosinophilic component of the infiltrate. ${ }^{11}$

In the second case demonstration in muscle of abnormal mitochondria, in the absence of a previous history of muscle disease and a negative family history and in the context of exposure to the NRTI didanosine strongly suggests that this was the aetiological agent. The patient's recovery when this drug was withdrawn lends further support to this hypothesis. Despite the frequency of reports of symptoms of myalgia and fatigue in clinical trials of NRTI, including didanosine, documented muscle disease caused by didanosine is very rare. $^{8101516}$ In the majority of reports which describe abnormalities of CPK, with or without symptoms of muscle weakness or fatigue, and which implicate didanosine as a cause of mitochondrially mediated myotoxicity, patients received zidovudine contemporaneously, or had received it until recently. ${ }^{15-17}$ In vitro, some studies have shown that didanosine exerts a toxic (mitochondrially mediated) effect on muscle, albeit less prominent than that induced by stavudine, zalcitabine, and zidovudine. ${ }^{4}{ }^{18}$ By contrast, other in vitro studies have failed to demonstrate that didanosine, at therapeutic doses, has a toxic effect on mitochondria in muscle. ${ }^{19}$ However, didanosine is clearly myotoxic, as shown by reports of didanosine induced rhabdomyolysis. ${ }^{4} 20$

These two cases add to the differential diagnosis of causes of muscle disease in this patient population. They also serve to underscore the importance of muscle biopsy in identifying 
the underlying pathology in HIV infected patients with nonspecific symptoms of muscle weakness, normal or minor elevations of CPK and normal EMG findings.

\section{ACKNOWLEDGEMENTS}

The authors thank Ms N Bhardwaj, Ms K Venner, and Mr S Dawodu, Institute of Neurology, for their expert technical assistance and Professor P Chiodini and Dr T Doherty, Hospital for Tropical Diseases, for helpful discussions.

\section{Authors' affiliations}

S Roedling, D Pearl, R F Miller, Patrick Manson Unit, University College London Hospitals, London WCIE 6AU, UK

H Manji, M G Hanna, Centre for Neuromuscular Disease, Department of Molecular Neuroscience, Institute of Neurology, University College London and National Hospital for Neurology and Neurosurgery, London WCIN 3BG, UK

J L Holton, Department of Molecular Neuroscience and Division of Neuropathology, Institute of Neurology, University College London and National Hospital for Neurology and Neurosurgery, London WCIN 3BG, UK

R F Miller, Centre for Sexual Health and HIV Research, Department of Primary Care and Population Sciences, Royal Free and University College Medical School, University College London, and Camden Primary Care Trust, Mortimer Market Centre, London WC1E 6AU, UK

Correspondence to: Dr Rob Miller, Centre for Sexual Health and HIV Research, Department of Primary Care and Population Sciences, Royal Free and University College Medical School, University College London, and Camden Primary Care Trust, Mortimer Market Centre, London WC1E 6AU, UK; rmiller@gum.ucl.ac.uk.uk

Accepted for publication 9 February 2004

\section{REFERENCES}

1 Illa I, Nath A, Dalakas M. Immunocytochemical and virological characteristics of HIV-associated inflammatory myopathies: similarities with seronegative polymyositis. Ann Neurol 1991;29:474-81.

2 Johnson RW, Williams FM, Kazi S, et al. Human immunodeficiency virusassociated polymyositis: longitudinal study of outcome. Arthritis Rheum 2003:49:172-8.
3 Medina DJ, Tsai C-H, Hsiung GD, et al. Comparison of mitochondrial morphology, mitochondrial DNA content, and cell viability in cultured cells treated with three anti-human immunodeficiency virus dideoxynucleosides. Antimicrob Agents Chemother 1994;38:1824-8.

4 Martin JL, Brown CE, Matthews-Davis N, et al. Effects of antiviral nucleoside analogues on human DNA polymerases and mitochondrial DNA synthesis. Antimicrob Agents Chemother 1994;38:2743-9.

5 Gherardi $\mathbf{R}$, Baudrimont $M$, Lionnet $F$, et al. Skeletal muscle toxoplasmosis in patients with acquired immunodeficiency syndrome; a clinical and pathological study. Ann Neurol 1992;32:535-52.

6 Chevalier X, Amoura Z, Viard JP, et al. Muscle lymphoma in patients with AIDS: a diagnostic problem with pyomyositis. Arthritis Rheum 1993;36:426-7.

7 Gherardi R, Belec L, Mhiri C, et al. The spectrum of vasculitis in human immunodeficiency virus-infected patients: a clinicopathologic evaluation. Arthritis Rheum 1993;36:1164-74.

8 Chariot $P$, Ruet $E$, Authier FJ, et al. Acute rhabdomyolysis in patients infected by human immunodeficiency virus. Neurology 1994;44:1692-6.

9 Manfredi RA, Motta RB, Patrono DB, et al. A prospective survey of laboratory markers of skeletal muscle damage during HIV disease and antiretroviral therapy. AIDS 2002;16:1969-71.

10 Simpson DM, Katzenstein DA, Hughes MD, et al. Neuromuscular function in HIV infection: analysis of a placebo-controlled combination antiretroviral trial. AIDS 1998; 12:2425-32.

11 Reveille JD. The changing spectrum of rheumatic disease in human immunodeficiency virus infection. Semin Arthritis Rheum 2000;30:147-66.

12 Itescu S, Braacato U, Buxbaum J, et al. A diffuse CD8 lymphocytosis syndrome in human immunodeficiency virus (HIV) infection: a host immune response associated with HLA-DR5. Ann Intern Med 1989:112:3-10.

13 Kazi S, Cohen PR, Williams F, et al. The diffuse infiltrative lymphocytosis syndrome: clinical and immunogenetic features in 35 patients. AIDS 1996; 10:385-91

14 Bocanegra TS, Vasey FB. Musculoskeletal syndromes in parasitic diseases. Clin Rheum Dis N Am 1993;19:505-13.

15 Abrams DI, Goldman Al, Launer C, et al. A comparative trial of didanosine or zalcitabine after treatment with zidovudine in patients with human immunodeficiency virus infection. N Engl J Med 1994;330:657-62.

16 Kieburtz KD, Seidlin M, Lambert JS, et al. Extended follow-up of peripheral neuropathy in patients with AIDS and AIDS-related complex treated with dideodyinosine. J Acquir Immune Defic Syndr 1992;5:60-4

17 Miller RF, Shahmanesh M, Hanna MG, et al. Polyphenotypic expression of mitochondrial toxicity caused by nucleoside reverse transcriptase inhibitors. Antiviral Ther 2003:8:253-7.

18 Benbrick E, Chariot P, Bonavaud S, Ammi-Said M, et al. Cellular and mitochondrial toxicity of zidovudine (AZT), didanosine (ddl) and zalcitabine (ddC) on cultured human muscle cells. J Neurol Sci 1997;49:19-25.

19 Masini A, Scott C, Calligaro A, et al. Zidovudine-induced experimental myopathy: dual mechanism of mitochondrial damage. J Neurol Sci 1999;166:131-40

20 Doronzo R, Geremia L, Sacilotto G, et al. 2', 3' dideoxyinosine-induced acute rhabdomyolysis. Clin Neuropathol 1993;12:S45. 